\title{
Identification and Molecular Characterization of Microbial Isolates from Purified Water Used in Pharmaceutical Industry
}

\author{
R. Gunaseelan ${ }^{1 *}$ (i) and T. Viswanathan ${ }^{2}$ (i) \\ ${ }^{1}$ Research and Development Centre, Bharathiar University, Coimbatore - 641 046, India. ${ }^{2}$ Department of \\ Microbiology, L.R.G Govt. Arts College for Women, Tirupur - 641 604, India.
}

\begin{abstract}
Purpose of the research work was to appraise the purified water quality by microbial analysis used in various manufacture in pharmaceutical industry. To have better control water systems samples are collected at regular intervals from the predefined user points. Water samples are checked for Total Aerobic Microbial Count (TAMC), Total Yeast and Mold Count (TYMC), Escherichia coli, Salmonella species, Staphylococcus aureus, Pseudomonas aeruginosa, Out of 2424 samples tested, $93.3 \%$ are positive, $6.6 \%$ are negative, $0.1 \%$ out of alert and no growth observed for TYMC, Pseudomonas aeruginosa, Escherichia coli, Staphylococcus aureus, Salmonella sp. Investigation performed for $\mathbf{0 . 1 \%}$ (4 samples) for which out of alert limit observed and identified the microbes such as Ralstonia solanacearum, Ralstonia mannitolilytica, Bacterium Sanya and Sphingomonas sp. based on the molecular characterization Based on the outcome of the results RO membrane replaced and increased the sanitization frequency. Further water samples were monitored as per the predefined frequency and observed that the results are within acceptance criteria.

Keywords: Microbial analysis, Purified water, Total Aerobic Microbial Count, Total Yeast and Mold Count, Molecular
\end{abstract} characterization.

\footnotetext{
*Correspondence: cvramguns@gmail.com; + 91 422-2428100

(Received: 18 May 2019; accepted: 30 June 2019)

Citation: Gunaseelan R. and Viswanathan T., Identification and Molecular Characterization of Microbial Isolates from Purified Water Used in Pharmaceutical Industry, J Pure Appl Microbiol., 2019; 13(3): 1815-1821. https://doi.org/10.22207/JPAM.13.3.58

(C) The Author(s) 2019. Open Access. This article is distributed under the terms of the Creative Commons Attribution 4.0 International License which permits unrestricted use, sharing, distribution, and reproduction in any medium, provided you give appropriate credit to the original author(s) and the source, provide a link to the Creative Commons license, and indicate if changes were made.
} 


\section{INTRODUCTION}

Water is commonly used major ingredient in pharmaceutical industry and known for its significant potential source of contamination ${ }^{1,4,6,10}$. There are numerous different grade of water used in pharmaceutical industry. i.e. Non-potable, potable water, purified water, Water for injection, Sterile water for injection etc. ${ }^{2}$. Therefore, it is vital that the water meets the specification as per the regulatory requirements and continuously makes available with pre-determined quality and quantity to make sure that there is no contamination of the manufactured goods or equipment ${ }^{11}$.

The source water can be used from natural or stockpile source ${ }^{3}$. Such water requires pretreatment to ensure that it meets drinking water standards ${ }^{1}$. Source water purified by following steps as mentioned in the (Fig-1). Deficit in piping system may leads to contamination of incoming water. Nomadic variations in temperature and growth of flora cause rise and fall in microbial content of supply water. Monitoring should be frequent enough to cover these variations. Samples are collected and tested as per the validation along with predetermined frequency to make sure that the method is in control and keep on to produce water of up to standard quality.

Organisms stay alive in a water system, as a free floating in the water or sticks to the wall of the pipe and tank. Organisms stick to the walls known as biofilm ${ }^{17,25,26}$. Biofilm easy to remove at early stage (Pre-Slime), it is hard to remove well developed biofilm from the water system. Eradicated but unharmed biofilms can become a nutrient supply for other bacteria. Common microorganisms recovered from water system samples include Gramnegative bacteria from the genera Pseudomonas, Ralstonia, Burkholderia, Stenotrophomonas, Comamonas, Methylobacterium, and various types of Pseudomonas-like organisms identified together as pseudomonads. These microbes originate from top soil and water tends to inhabit in water system distribution and purification system.

Water purification systems have to be disinfected using chemical or heat sanitization method. Suitable procedure and conditions shall be used for following control techniques possibly will used alone or in combination, tumultuous flow circulation to get rid of development of biofilm, shortest possible length of pipe work, dead legs in the pipe work should be minimized, UV radiation supply in pipe work, continuously maintain the water system greater than $65^{\circ} \mathrm{C}$, sanitizing the system at stipulated schedule using hot water temperature $\mathrm{m}\left(>70^{\circ} \mathrm{C}\right)$ and periodic chemical sanitization. When chemical sanitization performed, it is crucial to demonstrate that the chemical used has been isolated prior water used in the manufacturing process ${ }^{8}$.

The impact of microorganisms present in the product manufactured in non-sterile area should be assessed in terms of the use of the product, the natural history of the product and the probable damage to the user. Its manufacturer's choice to appraise their product, the technique it's manufactured, and set up an adequate action level of contamination, not to surpass the maximum, for the water system ${ }^{16}$.

Pharmaceutical companies declare that the source water providing the purified water system meets the suitable drinking water needs as per United States Environmental Protection Agency (USEPA). Situations could be initially water treatment system achieves drinking water quality and consequently purified water. A characteristic purification system that make available purified water which meets ionic and organic chemical standards, should be confined from microbial proliferation to diminish cross-contamination for use in cleaning and preparations in pharmaceutical industries and in health environment ${ }^{7,9}$.

R2A Agar is suggested by American Public Health Association (APHA) ${ }^{20,21}$ to use pour plate, spread plate or membrane filter procedure for assessing the heterotrophic plate count. R2A Agar media is prepared as per Reasoner and Geldreich ${ }^{22}$. Strained or ill-treated organisms during water treatment are unable to nurture on elevated nutrient media, since the faster growing organisms outgrow the former ${ }^{23}$. Therefore the use of a low nutrient medium like R2A Agar incubated for longer incubation periods allows strained organism to mature well. The fungi would not be likely to multiply in pharmaceutical category water due to their nutritional requirement ${ }^{10}$. In this study fungal monitoring has been included as a part of study.

Alert or action levels are usually set from the statistical assessment of the trend data of water monitoring data (Table 1). Rationale for 
routine monitoring of validated pharmaceutical water system is to conclude when the microbial counts are out of trend. The regulation is to make out excursion from a state of control based on charting ${ }^{12}$. This type of chart particularly helps in detection small but significant changes. A water system under control will have longer time intervals between excursions, whereas a water system moving out of a state of control will have shorter period between excursions ${ }^{10}$.

\section{MATERIALS AND METHOD}

\section{Chemicals and Reagents}

R2A agar (Catalog Number M962), Sabouraud Dextrose agar (Catalog Number MH063), MacConkey agar (Catalog Number MH081), MacConkey broth (Catalog Number $\mathrm{MH083),} \mathrm{Soyabean} \mathrm{casein} \mathrm{digest} \mathrm{broth} \mathrm{(Catalog}$ Number MH011), Rappaport vassiliadis salmonella enrichment broth (Catalog Number LQ104), Xylose-lysine-Deoxycholate agar (Catalog

Table 1. Limits and Frequency of Monitoring

\begin{tabular}{lccc}
\hline $\begin{array}{l}\text { Pharmacopeial } \\
\text { specification }^{(1)}\end{array}$ & $\begin{array}{c}\text { Alert } \\
\text { limit }\end{array}$ & $\begin{array}{c}\text { Action } \\
\text { limit }\end{array}$ & $\begin{array}{c}\text { Frequency of } \\
\text { monitoring }\end{array}$ \\
\hline $100 \mathrm{cfu} / \mathrm{mL}$ & $50 \mathrm{cfu} / \mathrm{mL}$ & $75 \mathrm{cfu} / \mathrm{mL}$ & $\begin{array}{c}\text { Once in } \\
\text { a month }\end{array}$
\end{tabular}

Note: CFU, colony-forming units.
Number MH031), Mannitol salt agar (Catalog Number MH118) and Cetrimide agar (Catalog Number MH024) supplied by Himedia. Culture Staphylococcus aureus ATCC 6538 Pseudomonas aeruginosa ATCC 9027 Escherichia coli ATCC 8739, Salmonella ATCC 14028, obtained from American type culture collection (ATCC). Gram's staining kit obtained from Himedia. Big Dye Terminator version 3. 1" Cycle sequencing kit. POP_7 polymer50 cm Capillary Array.

\section{Instrumentation}

ABI 3500 Genetic Analyzer, Incubators make thermolab, autoclave make machine fabric, laminar airflow unit make Esco, Analysis software:Seq Scape_v 5.2

\section{Methods}

Water samples are analysed for Total Aerobic Microbial Count (TAMC), Total Yeast and Mold Count (TYMC), Escherichia coli, Salmonella species, Staphylococcus aureus, Pseudomonas aeruginosa ${ }^{5}$.

In the membrane filtration method, a lowest amount volume of $10 \mathrm{~mL}$ of the sample passed aseptically into a sterile filtration set up containing a $0.45 \mu \mathrm{m}$ filter ${ }^{5,24}$. Vacuum is applied and the sample is drained all the way through the filter. All indicator organisms are hold on to or within the filter, further transferred to a R2A agar for TAMC and Sabouraud Dextrose Agar for TYMC. After recovery period, the bacteria become get

Table 2. Purified water sampling testing in pharmaceutical industry

\begin{tabular}{|c|c|c|c|c|c|c|c|c|c|c|c|}
\hline \multirow[t]{2}{*}{ Sample } & \multirow[t]{2}{*}{$\begin{array}{c}\text { No. of } \\
\text { samples }\end{array}$} & \multicolumn{2}{|c|}{ Positive } & \multicolumn{2}{|c|}{ Negative } & \multicolumn{2}{|c|}{ Pathogens } & \multicolumn{2}{|c|}{$\begin{array}{c}\text { Out of } \\
\text { alert limit }\end{array}$} & \multicolumn{2}{|c|}{ Pathogens } \\
\hline & & No. & $\%$ & No. & $\%$ & No. & $\%$ & No. & $\%$ & No. & $\%$ \\
\hline $\begin{array}{l}\text { Purified } \\
\text { water }\end{array}$ & 2424 & 2262 & $93.3 \%$ & 162 & $6.6 \%$ & 0 & $0 \%$ & 4 & $0.1 \%$ & 0 & $0 \%$ \\
\hline
\end{tabular}

Out of 2424 samples tested, $93.3 \%$ are positive, $6.6 \%$ are negative, $0.1 \%$ out of alert and there is no growth observed for TYMC, Pseudomonas aeruginosa, Escherichia coli, Staphylococcus aureus, Salmonella sp.

Table 3. Identification and Molecular Characterization of microbial isolates

\begin{tabular}{|c|c|c|c|c|}
\hline S.No. & Culture ID/Accession & Grams staining & Shape & Identified \\
\hline 1 & EI-138/KY773618 & Gram Negative & Rod & Ralstonia solanacearum \\
\hline 2 & $\mathrm{EI}-128 / \mathrm{KX} 845570$ & Gram Negative & Rod & $\begin{array}{c}\text { Ralstonia mannitolilytica } \\
\text { strain SN82F48 }\end{array}$ \\
\hline 3 & El-135/MG738363 & Gram Negative & Rod & Bacterium Sanya2013001 \\
\hline 4 & El-136/MG738362 & Gram Negative & Rod & Sphingomonas sp. R2S2 \\
\hline
\end{tabular}


used to the new conditions. Petri plate transferred to an incubator at $30-35^{\circ} \mathrm{C}$ for 5 days for TAMC and $20-25^{\circ} \mathrm{C}$ for 5 days for TYMC. Visually individual colonies formed are counted, and the outcome is articulated in numbers of "colony forming units" (CFU) per $100 \mathrm{~mL}$ of sample ${ }^{24}$.

For pathogen testing, transferred $10 \mathrm{~mL}$ of sample in $100 \mathrm{~mL}$ SCDB (Soyabean casein digest broth) are incubated at $30-35^{\circ} \mathrm{C}$ for $18-24$ hours (Solution A). Transferred $1 \mathrm{~mL}$ of sample $-A$ into $100 \mathrm{~mL}$ MacConkey agar incubated at $42-44^{\circ} \mathrm{C}$ for $24-48$ hours, further subcultured on MacConkey agar incubated at $30-35^{\circ} \mathrm{C}$ for 18 - 72 hours for Escherichia coli. Transferred 0. $1 \mathrm{~mL}$ of enrichment sample (Solution A) to tube containing $10 \mathrm{~mL}$ of Rappaport vassiliadis salmonella enrichment broth at $30-35^{\circ} \mathrm{C}$ for 18 - 24 hours, again subcultured on Xylose-lysineDexycholate agar media and incubated at $30-35^{\circ} \mathrm{C}$ for $18-48$ hours for Salmonella species. Streaked a loopful of enrichment sample on plate of Cetrimide Agar and incubated at $30-35^{\circ} \mathrm{C}$ for $18-72$ hours for Pseudomonas aeruginosa. Streaked a loopful of enrichment sample (Solution A) on a plate of Mannitol salt agar and incubated at $30-35^{\circ} \mathrm{C}$ for 18 -72 hours. The possible presence of pathogen is specified by the growth and colony characteristics and compared with positive control ${ }^{13,14,15}$.

\section{RESULTS}

Water samples collected from various points from the generation as well as user points for one year in the frequency of one month were tested for microbial analysis. Total number of samples collected and results observed are tabulated in Table 2.

\section{DISCUSSION}

Investigation performed for $0.1 \%$ (4 samples) for which out of alert limit observed during the period was further identified by molecular characterization are tabulated in the Table 3.

\section{Identification of Microbial Isolate Primary screening}

The Out of limit (OOL) colonies were (named as El-128, El-135, El-136 and El-138) isolated and performed grams staining by using microscope technique. Grams staining will provide information's i. e. cell arrangement (single cell, cluster and clumps), shape (rod or cocci) and grams-staining characteristics. Transferred a loopful of the liquid culture to the surface of a clean slide, spreaded over small area and allowed to dry the layer. Dried layer fixed by passing it through the bunsen flame for two or three times without divulging the dried film openly to the flame. The slide should not be so hot as to be uncomfortable to the touch. Pour crystal violet solution on slide for up to one minute then wash off with water less than 5 second and drain. Flooded slide with Gram's lodine solution, and allowed to act for about one minute. Wash with water and drain. Get rid of water from slide and blot, so that alcohol used for decolorization not watered down. Pour 95\% alcohol on slide for 10 seconds and wash with water. (Smears that are extremely thick may need extensive decolonization. As it is more sensitive and erratic step of the procedure, and requires familiarity how much to decolorize) and drained the slide. Flooded slide with safranin solution and allowed to counter stain for 30 seconds. Wash off with water. Drain and blot dry with bibulous paper.

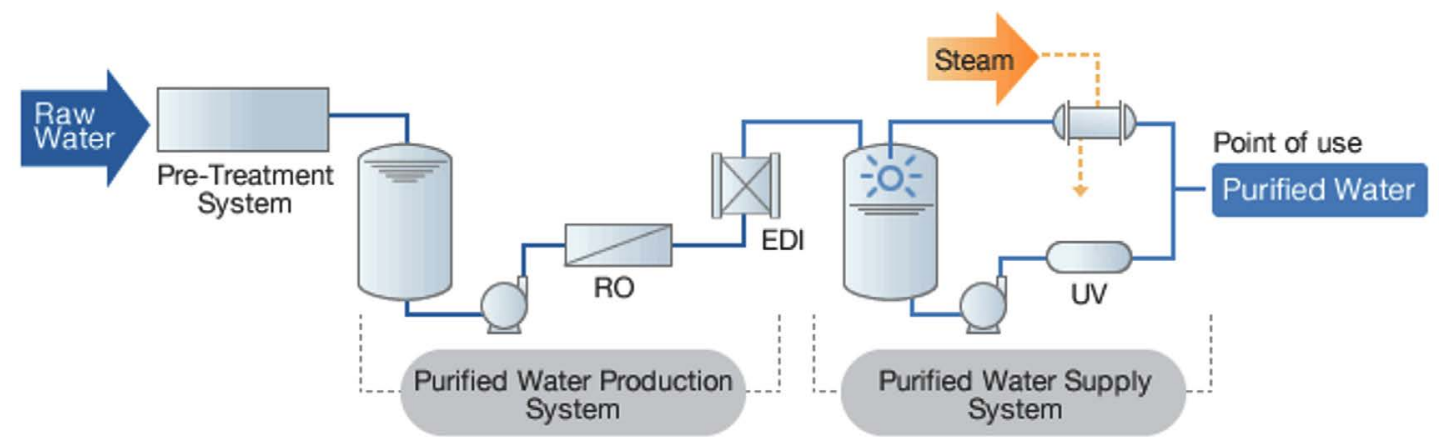

Fig. 1. Purified water process in pharmaceutical industry. 
The slides of bacteria were inspected under the oil immersion lens.

\section{Molecular characterization}

Genomic DNA was extracted from 4 isolates following DNAzol-based cell lysis protocol and the lysates were purified on DNA-binding columns. Polymerase chain reaction (PCR) magnification was performed in $\mathrm{ABI}-2720$ thermal

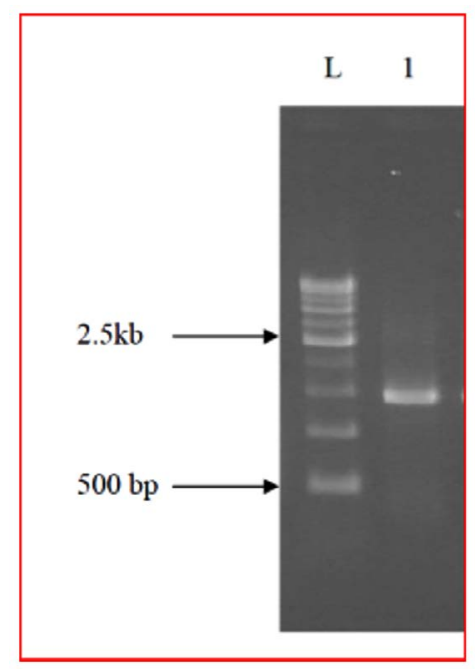

Lane description:

1. Sample EI-138, L. 500 bp ladder

Fig. 2. 16s rDNA fragment - Bacterial sample El-138 loaded on $1 \%$ Agarose gel.

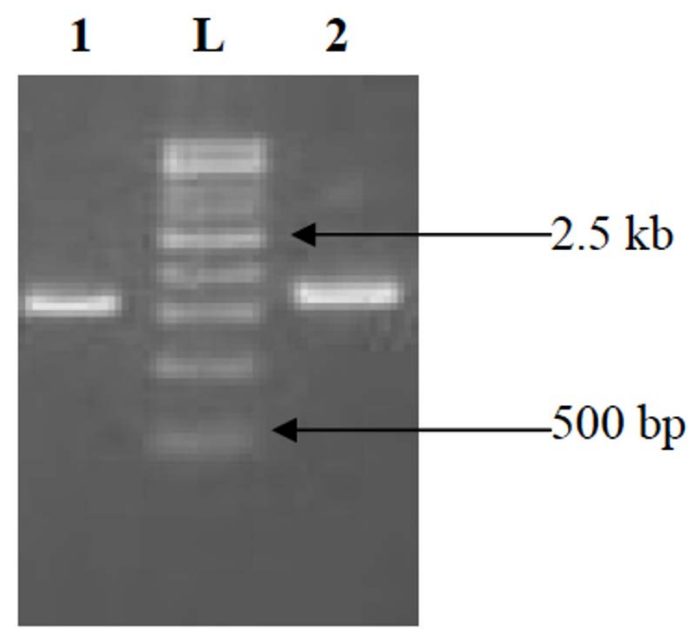

Lane description:

1. El-136, L - 500 bp ladder, 2. El-135

Fig. 3. 16s rDNA fragment from bacterial sample El-136 \& El-135. The size $\sim 1.5 \mathrm{~kb}$ PCR amplified product cyclers using $341 \mathrm{~F}$ and $907 \mathrm{R}$ as primers ${ }^{19}$. The PCR magnification blend contained $0.2 \mathrm{mmol} / \mathrm{L}$ (each) dNTP, $400 \mathrm{nmol} / \mathrm{L}$ (each) primer, $5 \mathrm{mmol} / \mathrm{L} \mathrm{MgCl}$, and $1 \mathrm{U}$ Taq polymerase in a final volume of 50 l. First step is denaturation at $94^{\circ} \mathrm{C}$ for $3 \mathrm{~min}$ followed by 30 cycles of PCR reaction run as follows: denaturation at $94^{\circ} \mathrm{C}$ for $1 \mathrm{~min}$, annealing at $55^{\circ} \mathrm{C}$ for $45 \mathrm{~s}$, and extension at $72^{\circ} \mathrm{C}$ for $1 \mathrm{~min}$. In addition, a final extension at $72^{\circ} \mathrm{C}$ for $10 \mathrm{~min}$ was added. The final products were evaluated by electrophoresis in $1.0 \%$ agarose gel and purified with PCR Cleanup Kit Refer Fig. 2-4. Sequences were determined in an ABI-3500 XL Genetic Analyzer using 341F as a sequencing primer, and their nearby matches were found by blasting against the short and nearly accurate matches from NCBI (National Center for Biotechnology Information) databases. Sequences were associated and the phylogenetic tree was formed using DNAMAN package (Lynnon Biosoft, Canada) with advancement distances method (boot-strapping 100-times).

The results of molecular characterization of bacterial isolate are as below:

\section{Sample: El-138}

Ralstonia solanacearum SN82F48. Accession No. KY773618: The next closest homologue was found to be Ralstonia mannitolilytica strain OS8. 6165 ribosomal RNA gene, partial sequence.

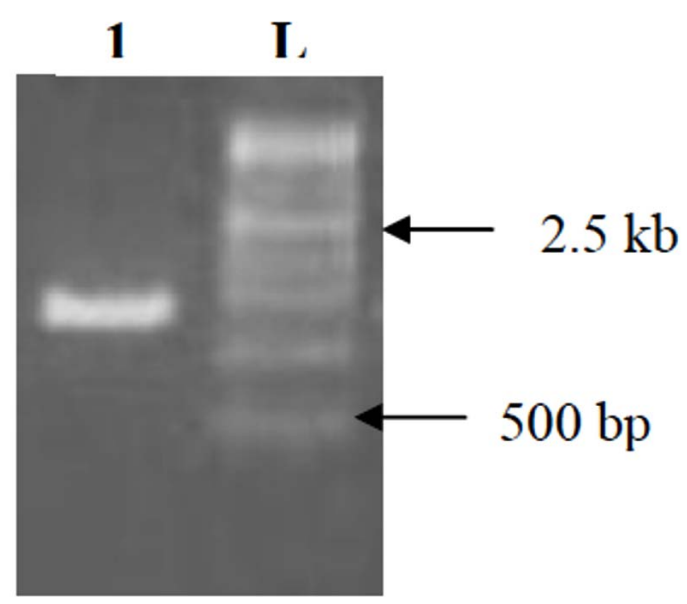

Lane description:

1. El-128 (1.5Kb), L. 500 bp Ladder

Fig. 4. 16s rDNA fragment from Bacterial sample El-128 on $1 \%$ Agarose gel 


\section{Sample: El-135}

The Microbe was found to be most similar Bacterium Sanya2013001 Accession No. MG738363 16S ribosomal RNA gene, partial sequence. Subsequently next homologue was found to be Ralstonia mannitolilytica strainOS8. 616 S ribosomal RNA gene, partial sequence.

\section{Sample: El-136}

The Microbe was found to be most Sphingomonas sp. R2S2 Accession No. MG738362 $16 \mathrm{~S}$ ribosomal RNA gene, partial sequence. Subsequently next homologue was found to be uncultured bacterium clone HL201305-12916S ribosomal RNA gene, partial sequence.

\section{Sample: El-128}

The Microbe was found to be most similar to Ralstonia mannitolilytica strain SN82F48 Accession No. KX845570 chromosome 1, complete sequence. Subsequently next homologue was found to be uncultured bacterium clone Ap. baFDM- HN-1-46 16S ribosomal RNA gene, partial sequence.

\section{CONCLUSION}

Based on the validation data outcome concluded that, to maintain the quality of water periodic monitoring should be performed. Periodic maintenance and filter replacement will ensure the high-quality of microbial control in the water. To scrutinize the water quality, samples should be analyzed for Total Aerobic Microbial Count (TAMC), Total Yeast and Mold Count (TYMC), Escherichia coli, Salmonella species, Staphylococcus aureus and Pseudomonas aeruginosa. In case of failure, investigation should be performed to identify the exact root cause i,e., filter, RO membrane should be replaced and frequency of sanitization shall be increased to have a better control on microbial proliferation.

\section{ACKNOWLEDGMENT}

The authors would like to express the gratitude to the management of Bharathiar University and Sequent Research limited for all the support.

\section{CONFLICT OF INTEREST}

The authors declares that there is no conflict of interest.

\section{AUTHORS' CONTRIBUTION}

All authors listed have made a substantial, direct and intellectual contribution to the work, and approved it for publication.

\section{FUNDING}

None.

\section{DATA AVAILABILITY}

All datasets generated or analyzed during this study are included in the manuscript.

\section{ETHICS STATEMENT}

Not applicable.

\section{REFERENCES}

1. United States Pharmacopeia (USP) 41 NF 36 Chapter $<1231>$ chapter Water for Pharmaceutical Purposes, 2018; 7742-7778

2. Department of health, education, and welfare public health service food and drug administration water for pharmaceutical use. http://www. fda. gov/iceci/inspections/inspectionguides/ inspectiontechnicalguides/ucm072925. htm.

3. WHO good manufacturing practices: water for pharmaceutical use. Annexure -2, https://www. who. int/medicines/areas/quality_safety/quality_ assurance/TRS986annex2. pdf.

4. ASTM Standard Specification for Reagent Water, Designation D1193-91, In: Annual book of ASTM Standards. American Society for Testing and Materials, Philadelphia, PA. Water and Environmental Technology, 1993; 11(1): 45-47.

5. Bordner R., Winter J. and Scarpino P. (ed). Microbiological Methods for Monitoring the Environment: Water and Wastes. EPA-600/8-78-017, Environmental Monitoring and Support Laboratory, $\mathrm{U}$. S. Environmental Protection Agency, Cincinnati, $\mathrm{OH}$, 1978.

6. CDER Guidance for Industry Sterile Drug Products Produced by Aseptic Processing-Current Good Manufacturing Practice. https://www. fda. gov/ media/71026/download, 2004.

7. Penna V. T. C. , Martins S. A. M and Mazzola P. G. Identification of bacteria in drinking and purified water during the monitoring of a typical water purification system. BMC Public Health, 2002; 2: 13-23. https://doi.org/10.1186/1471-2458-2-13.

8. Florjanic M. and Kristl J. Microbiological quality assurance of purified water by ozonization of storage and distribution system. Drug Develop Industr Pharm 2006; 32(10),1113-1112. https://doi. org/10.1080/03639040600920614.

9. N. C. Magar, R. P. Devale and A. P. Khadke. A review on water used in pharma industry, European Journal of Pharmaceutical and Medical Research 2017, 4(06), 226-236.

10. Anthony M. Cundell, Microbial Monitoring of Potable 
Water and Water for Pharmaceutical Purposes In: Microbial Contamination Control in the Pharmaceutical Industry, ed. Jiminez, L. and Marcel-Dekker, 2004; 142: 45-75.

11. Annelie Hultqvist. Practical guidelines for qualifying purified water systems Pharmaceutical Technology Europe 2007; 19(12).

12. WHO good manufacturing practices: water for pharmaceutical use: WHO Technical Report Series, No. 970, Annex 2. WHO Expert Committee on Specifications for Pharmaceutical Preparations Fortysixth report. https://apps. whoiny/medicinedocs/ documents/s19832en/s19832en. pdf.

13. United States Pharmacopeia (USP) 41 NF 36 chapter -61 Microbiological examination of non-sterile products: tests for specified microorganisms, 2018; 5965-5971.

14. United States Pharmacopeia (USP) 41 NF 36 chapter <62> Microbiological examination of non-sterile products: microbial enumeration tests 2018 ; 59715978.

15. Indian pharmacopeia 2. 2. 9 Microbial contamination in non-sterile products. (IP2014) page 38-50.

16. US Food and Drug Administration. Guide to inspections of high purity water systems, high purity water systems (7/93), 2009.

17. William J. Bruno, Nicholas D. Socci, and Aaron L. Halpern. Weighted Neighbor Joining: A LikelihoodBased Approach to Distance-Based Phylogeny Reconstruction, Mol. Biol. , 2000; 17(1): 189-197. https://doi.org/10.1093/oxfordjournals.molbev. a026231.

18. E. O. Wiley, D. R. Brooks, D. Siegel-Causey, V. A. Funk. The Compleat Cladist: A Primer of Phylogenetic Procedures 1991. https://doi.org/10.5962/bhl. title.4069.

19. Teske A. , Wawer C. , Muyzer G. , Ramsing N. B. Distribution of sulfate-reducing bacteria in a stratified fjord (Mariager Fjord, Denmark) as evaluated by mostprobable-number counts and denaturing gradient gel electrophoresis of PCR-amplified ribosomal DNA fragments Molecular Ecology Group, Max Planck Institute for Marine Microbiology, Bremen, Germany. Appl. Environ. Microbiol., 1996; 62(4): 1405-15.

20. Baird R. B. , Eaton A. D., and Rice E. W. , (Eds), Standard Methods for the Examination of Water and wastewater, Wastewater, $20^{\text {th }}$ Ed. , American Public Health Association, Washington, D. C. , 2015.

21. Salfinger Y. , and Tortorello M. L. Fifth (Ed), Compendium of Methods for the Microbiological Examination of Food, $5^{\text {th }}$ Ed., American Public Health Association, Washington, D. C., 2015. https://doi.org/10.2105/MBEF.0222.

22. Reasoner D.J. and Geldrech E.E., Appl. Eviron. Microbiol. 1985; 49: 1.

23. Collins V. J. and Willoughby J.G., Arch. Microbiol., 1962; 43: 294. https://doi.org/10.1007/BF00405972.

24. World health organisation., Water sampling and analysis https://www. who.int/water_sanitation) health /dwq/2edvol3d. pfd.

25. Tsagkari E. and W. T. Sloan Turbulence accelerates the growth of drinking water biofilms Biopro. Biosyst. Eng. 2018; 41: 757-770. https://doi.org/10.1007/s00449018-1909-0.

26. O'Toole G. A. and R. Kolter Initiation of biofilm formation in Pseudomonas fluorescens WCS365 proceeds via multiple, convergent signaling pathways: a genetic analysis. Mol. Microbiol., 1998; 28(3): 449-61. https://doi.org/10.1046/j.1365-2958.1998.00797.x. 